\title{
La Supranacionalidad y la Descentralización Infranacional en la Comunidad Andina. Decisión 501 en la Frontera Colombia - Venezuela*
}

Ana Marleny Bustamante ${ }^{* *}$

Resumen: Este trabajo muestra que los avances en la integración andina y en la descentralización infranacional de Colombia y Venezuela han sido insuficientes y han tomado direcciones y significados diferentes, por lo que la cooperación o integración transfronteriza se dificulta. Factores externos, la falta de élites comprometidas con la integración, los recelos, temores y odios entre los países permiten un cierto nivel normativo de supra e infranacionalidad en el Estado pero poco se logra en la integración de hecho a pesar de la participación de actores de las fronteras.

Palabras-claves: Supranacionalidad, Infranacionalidad, Descentralización, Comunidad Andina, Frontera.

Abstract: This paper shows that the Andean integration and the infranational decentralization of Colombia and Venezuela have not been enough and have different directionsand meanings, making cooperation and transborder regional integration difficult. External factors, the lack of an elite engaged in integration, distrust, fears and hatreds between the countries allow a certain normative level of supra and infranationality in the State but very little in the factual integration in spite of the participation of actors from the border regions.

Keywords: Supranationality, Infranationality, Decentralization, Andean Community, Border.

\footnotetext{
* Mi agradecimiento al CDCHT de la Universidad de Los Andes - Venezuela por el financiamiento para presentar este trabajo en el 52 ICA, a celebrarse en Sevilla del 17 al 21 de julio de 2006. El trabajo es parte de los resultados del proyecto código: NUTA-H-175-03-09-AA. También agradezco a Rita Giacalone, Giovanny Molano, Hernando Arcinegas y Douglas Izarra quienes leyeron e hicieron comentarios importantes a las primeras versiones de este trabajo.

** PhD, Centro de Estudios de Fronteras e Integración, Universidad de Los Andes, Venezuela. E-mail: apernia5@hotmail. com. Recebido em 27/11/06 e aceito em 11/12/06.
} 


\section{Presentación}

Las versiones de supranacionalidad visibles en la integración andina único ejemplo en América latina donde se ha avanzado en esta dirección - y de descentralización política en cada país miembro, antes que peticiones autónomas de los movimientos sociales o la sociedad civil y respuestas igualmente independientes de los gobiernos de la subregión, han sido formas "particulares" de apropiarse de una tendencia o exigencia generalizada por parte de distintos entes internacionales como lo son los organismos multilaterales o los propios órganos de integración o la corriente político-económica del momento. Las soluciones o respuestas aparentes a dicha tendencia parecieran ser en realidad adaptaciones para seguir encubriendo viejos recelos y temores que han marcado las relaciones diplomáticas entre los países de la subregión y para mantener el estado de cosas sin intentar cambiarlas de manera positiva tanto al interior como hacia el exterior de los países.

La supranacionalidad y la infranacionalidad son dos conceptos que han surgido a raíz del avance y profundización de la globalización y la integración regional. Ambas representan las presiones sobre el Estado-nación; la primera se refiere a las externas provenientes desde los órganos de integración y la segunda a las derivadas de los órganos político-administrativos en los que se ha dividido el Estado o de organizaciones civiles que actúan en su interior. Se estima que estas fuerzas actuando simultáneamente debilitan el poder del Estado-nación como depositario principal del poder y de las lealtades de los países y sus poblaciones.

El análisis del impacto de la supranacionalidad y la descentralización infranacional sobre el Estado -nación o al menos sobre los gobiernos centrales en América Latina no va en la misma dirección que en Europa pues aquí la supranacionalidad o la descentralización infranacional no han adquirido la fortaleza para desafiar el poder del gobierno central por lo que éste no requiere hacer grandes adecuaciones y concesiones derivadas de las primeras. No obstante, las comunidades fronterizas, en algunos casos han logrado imponer la integración de hecho sobre la integración de derecho. Para ejemplificar tal situación se tomará a Colombia y Venezuela, dos países que históricamente, a pesar de no haber ido a la guerra por el territorio durante su vida republicana, se han recelado y obstruido constantemente 
en sus posibilidades de desarrollo. Sus políticas exteriores e incluso ciertos momentos de sus políticas domésticas han estado asociadas al "síndrome de la pérdida territorial" o a la necesidad de "consolidar el territorio". Hasta bien avanzada la década del ochenta del siglo XX, las relaciones diplomáticas entre estos dos países giraron en torno a la delimitación territorial, la cual aún se mantiene vigente con la delimitación pendiente al Noroeste del Golfo de Venezuela. Esta última, el cual se convirtió en prioritaria para la agenda de la política exterior de cada país respecto al otro hasta los años ochenta del siglo pasado, a pesar que venían formando parte de acuerdos de cooperación e integración importantes en la región, los cuales adquieren un nuevo impulso a partir de la década de los noventa. El recelo y desconfianza también es visible en otras áreas de política como por ejemplo en la ejecución de la Decisión 521 de la Comunidad Andina (CAN) sobre Zonas de Integración Fronteriza (ZIFs), que a pesar de haber sido obstaculizada por los gobiernos centrales logró su creación con el respaldo de las entidades fronterizas.

El trabajo constará de cuatro partes: la primera hará una discusión sobre el avance de la supranacionalidad e infranacionalidad en América Latina y el proceso de la reforma del Estado/descentralización en Colombia y Venezuela; la segunda hará una revisión histórica de las relaciones binacionales Colombo-venezolanas destacando los puntos álgidos de las relaciones; la tercera revisará el proceso de integración andino enfatizando la participación de Colombia y Venezuela en la CAN y tomará la difícil articulación entre supranacionalidad y descentralización en la frontera de Norte de Santander - Táchira considerado el espacio más dinámico entre los dos países. Finalmente se hará una discusión sobre las consecuencias de tales situaciones en el desarrollo presente y a futuro tanto de la recientemente creada ZIF en el espacio de frontera colombo-venezolano mencionado; como de la descentralización y la supranacionalidad.

\section{Supranacionalidad y descentralización en América Latina Impacto de la supranacionalidad en lo Estado-Nación}

La integración regional impacta al Estado-nación de por lo menos tres formas según el grado de desarrollo del grupo de países y del grado de avance alcanzado en el proceso integrador; a saber: sobre los países desarrollados, 
sobre los países que ostentan grados disímiles de desarrollo y sobre los menos desarrollados o subdesarrollados, aunque ha habido pocos avances en esta discusión para los dos últimos casos.

En el primer caso, que podría considerarse el caso de la Unión Europea (UE) también se presentan al menos tres versiones: La integración no debilita al Estado-nación, mas bien parece fortalecerlo (MILWARD, 1994; MORAVCSICK, 1993). La integración está produciendo erosiones severas en la soberanía del Estado-nación y está construyendo una nueva entidad supranacional (GEORGE, 1991; ALTER, 1998) y finalmente está la posición que señala a la integración como un proceso de múltiples niveles de gobierno en el que a pesar del control del Estado ciertamente hay ciertas cesiones de soberanía (MARKS, HOOGE, BLANK, 1996).

El segundo caso se refiere al tipo de integración más reciente surgida al mismo tiempo que el regionalismo abierto y se refiere a la integración entre países con grados de desarrollo muy disímiles, como lo es el caso del Tratado de Libre Comercio de América del Norte entre México, Estados Unidos y Canadá, conocido como TLCAN (o NAFTA según sus siglas en Inglés), La propuesta del Área de Libre Comercio para las Americas (ALCA), o lo que eventualmente pudiera estar ocurriendo con la incorporación a la UE de países selectos de Europa del Este, los cuales presentan un menor grado de desarrollo y poder respecto a los miembros de la UE de los quince. Lo novedoso de este tipo de acuerdos es que van más allá de los acuerdos de comercio tradicionales y vinculan al comercio con el ambiente, trabajo, arreglo de disputas, derechos de propiedad intelectual, finanzas, agricultura, energía, y otros aspectos que no estaban vinculados a los temas tradicionales del GATT. Las características de esta nueva ola de regionalismo son: la ampliación y profundización de los temas, apertura y desinstitucionalización de los procesos de integración y ello supone el abandono de las ideas tradicionales en las organizaciones de integración regional, la desestimación de los avances y explicaciones optimistas del regionalismo basadas en el neofuncionalismo y la adopción del intergubernamentalismo propio del neorrealismo (AXLINE, 1994; SIDERI, 1996; PAYNE, 1996; BHAGWATI, 1993) Así, aunque el TLCAN y la propuesta ALCA no son un simple acuerdo intergubernamental, sus textos tampoco aportan elementos para detectar cambios profundos en 
las estructuras de los países involucrados por lo que se ha discutido poco sobre erosiones de soberanía o sobre el Estado-nación, derivados de la constitución de estos acuerdos. La discusión tiende a centrarse alrededor de las heterogeneidades en los niveles de desarrollo entre los países miembros y del predominio de los países más fuertes sobre los más débiles (FRAMBESBUXEDA, 1994).

El tercer caso es el de los procesos de integración entre países subdesarrollados, como el caso de la experiencia latinoamericana antes de la aparición del TLCAN y la propuesta ALCA. Hay distintos factores que obstaculizan los avances ciertos de la integración entre estos países. Entre ellos se mencionan las limitaciones para alcanzar la integración física (PELKMANS, 1993) y el alto grado de dependencia y vulnerabilidad del sector externo (KAPLAN, 1969; STEIN, STEIN, 1979; CEPAL, 2005, ALADI/CEPAL/SELA, 1996), la inestabilidad política y el nacionalismo (HAAS, 1967; BUSTAMANTE, CARABALLO, 2005) que continúan afectando la posibilidad de construir un bloque con suficiente capacidad de negociación en lo externo y con suficiente cohesión interna como para avanzar en la construcción de políticas comunes de mediano y largo plazo. Tomando en consideración estas limitaciones, la integración entre países subdesarrollados no ha avanzado lo suficiente para evidenciar erosiones serias a su ya debilitada soberanía nacional, la cual se atribuye a la forma en que estos países se han insertado al escenario internacional. Sin embargo, el debate sobre las posibles erosiones a la soberanía a los Estado-nación que se produjo en Europa, en los años sesenta y setenta del siglo XX, influyó sensiblemente en el tipo de instituciones de integración creadas y en las atribuciones otorgadas a las mismas (ICE, 1974; KAPLAN, 1969, 1976, 1989), por lo que las mismas son esencialmente intergubernamentales.

No obstante la limitada integración económica y los escasos avances supranacionales, los países de la CAN logran crear instituciones con rasgos supranacionales. Los avances dados, particularmente del Derecho de la Integración, hacen que procesos de integración como el andino se conviertan en motivo de preocupación para muchos gobiernos y analistas del proceso de integración latinoamericano. Desde los años cincuenta del siglo XX, los gobiernos latinoamericanos evitaron asumir compromisos más allá de 
los comerciales y estrictamente económicos, así se obvió la creación de instituciones que amenazaran con disminuir el poder de los gobiernos en la integración. El Acuerdo de Cartagena, alcanzado en 1969, extrañamente se convierte en el primer Acuerdo que marca algún alejamiento de esta tendencia latinoamericana. Mediante el mismo se privilegia e incorpora parte de la experiencia europea sobre una institucionalidad que privilegia el proceso de integración regional a fines y objetivos colectivos antes que a los individuales de cada país. Así, la hoy Comunidad Andina fue avanzando hasta crear una institucionalidad que incluye: la Comisión, el Parlamento Andino, el Tribunal Andino de Justicia (TAJ) y la Secretaría General (anterior Junta); a las cuales se les han unido, a partir de 1996, las Reuniones Presidenciales y del Consejo de Ministros de Relaciones exteriores. La CAN ha elaborado, a través de la Comisión y del Tribunal Andino de Justicia, una estructura jurídica, que al igual que la Unión Europea (UE) ha puesto en jaque concepciones tradicionales del Derecho, las cuales se fundamentan en la aceptación que el Estado-nación es el objeto fundamental del Derecho Internacional. El TAJ coloca a la normativa comunitaria como preeminente a las legislaciones nacionales y es de aplicación directa e inmediata en los países de la CAN.

A pesar de los avances dados en la Comunidad Andina hasta 1996 y que los gobiernos de los países miembros parecen colocar a la integración latinoamericana y andina como prioridad política en sus constituciones nacionales, paradójicamente, es a partir de esa década, cuando Latinoamérica empieza a avanzar en una tendencia de "desinsitucionalización" de los procesos de integración y, en ello, la misma CAN sufrió cambios como lo fueron la eliminación de la Junta y sustitución por la Secretaría General y la incorporación de las Reuniones Presidenciales y de Cancilleres como instancias $\mathrm{u}$ órganos principales del Acuerdo. De la misma manera el MERCOSUR, el Grupo de los Tres (G-3), el Mercado Común Centroamericano (MCCA) entre otros, rechazaron toda mención a una posible cesión de soberanía, aunque fuese limitada, y por ende evitaron la creación de instituciones de carácter regional que permitieran darle coherencia a la dispersión de acuerdos. Aún así, la supranacionalidad de la CAN convive con estas fuerzas desinstitucionalizadoras e intergubernamentales; 
las cuales tampoco parecieran estar decididas a eliminar por completo los avances y logros alcanzados, especialmente en materia de protección frente a terceros y de cohesión interna con miras a la elevación de los niveles de desarrollo, disminución de las desigualdades o de corrección de las asimetrías socioeconómicas entre países.

\section{El proceso de la reforma del Estado y de descentralización América Latina}

Las políticas públicas de descentralización conducentes al desarrollo regional y local en América Latina si bien se iniciaron hacia la segunda mitad de los años cuarenta del siglo XX inmediatamente después de la Segunda Guerra Mundial, no fueron visibles y asumidas como tales hasta la década de los ochenta.

Entre los cuarenta y ochenta la preocupación por los desniveles en el desarrollo pasó por distintas concepciones teóricas y esfuerzos. En un primer momento se hizo énfasis en la planificación de las cuencas hidrográficas con proyectos como la Corporación del Santa en Perú en 1943, la Comisión del Papaloapan en México en 1947, y la Corporación del Valle del Cauca en Colombia en 1954, entre otros. Las políticas de desarrollo regional asociadas a la planificación exhibieron instrumentos como la regionalización que tuvo en Venezuela su expresión en la creación de la Corporación Venezolana de Guayana (CVG) en 1960 CORPOANDES en 1964 y más tarde la regionalización político administrativa que dividió al país en siete regiones de desarrollo durante el gobierno de Rafael Caldera. Más tarde se intentarían políticas asociadas a las teorías de Perroux sobre los polos de crecimiento, las estrategias de integración económico-espacial, las Corporaciones de Desarrollo Regional y los Programas de Desarrollo Regional Integrado (MONCAYO JIMÉNEZ, 2005).

La década de los ochenta coincidió con la crisis de la deuda pública externa en la región y también con el auge de las políticas neoliberales que relegaron al Estado de Bienestar y al papel protagónico del Estado en la conducción de la economía (IBARRA, 2004; MONCAYO JIMÉNEZ, 2005). La visión alternativa para superar la crisis hacía énfasis en la eficiencia y capacidad del Estado antes que en su intervención en la economía, por 
lo que la descentralización se tornó fue la respuesta apropiada para salir del desacreditado Estado centralista e interventor en la economía. Siendo ésta una recomendación proveniente además por los "think tanks" de los organismos multilaterales y de la corriente teórico-ideológica dominante en el momento, se esperaba que la descentralización sentara las bases para un desarrollo local competitivo, asegurara la equidad social a escala territorial, aumentara la eficiencia y transparencia de las administraciones públicas en América Latina (FINOT, 2003). Sin embargo, la transferencia de competencias no ha avanzado con la misma velocidad que la transferencia de recursos a los niveles infranacionales ni los actores locales se han involucrado activamente con posiciones características del proceso de decisión política conocido como de "abajo hacia arriba" puesto que la cultura política de la participación en América latina es bastante limitada y no tiene arraigo en las bases de la población.

Los países andinos adoptaron, al igual que los países desarrollados y el resto de América Latina el rumbo de la aplicación de las políticas neoliberales y de descentralización. Así en Bolivia la descentralización fue aprobada durante la administración de Sánchez de Losada, mediante la Ley de Descentralización Administrativa de 1996, la cual conjuntamente con la Ley de Participación Popular (1994) transfieren competencias y desconcentran poderes. La primera desconcentra hacia los municipios competencias de orden administrativo mientras que la segunda transfiere a los municipios competencias políticas, económicas y administrativas. Contrariamente, Perú, que había avanzado, al menos formalmente, hacia la descentralización con la Constitución de 1979 pues había definido al Estado como "unitario, representativo y descentralizado" y en 1984 había aprobado la Ley Orgánica de las Municipalidades otorgándole competencias importantes a los municipios, con las reformas estructurales y la conformidad del Consenso de Washington; abandona este rumbo y adopta formas centralistas de gestión territorial, según se plasma en la Constitución de 1993. Perú retoma la descentralización durante el gobierno de Toledo al aprobar la Reforma Constitucional, la Ley de Bases de la Descentralización y la Ley Orgánica de los Gobiernos Regionales. Ecuador por su parte, conteste con el movimiento reformador del Estado y de la Economía, aprueba la Modernización el 
Estado en 1993. En 1997, aprueba la Ley Especial de Descentralización del Estado y Participación Social y la Ley Especial de Distribución del 15\% del Presupuesto General del Estado para los Gobiernos Seccionales. Al igual que Bolivia, Colombia y Venezuela, Ecuador eleva la descentralización a rango constitucional (MONCAYO JIMÉNEZ, 2005, p. 45-64).

En la misma sintonía de las reformas estructurales Colombia y Venezuela emprenden sus procesos de reforma del Estado. Venezuela, inicia decididamente la descentralización política, administrativa y fiscal a mediados de los años ochenta pero ello sólo se logra iniciar en 1989 con la primera elección de gobernadores y alcaldes para luego en 1993 iniciar la descentralización fiscal. Colombia, por su parte, inspirado en el compromiso y el marco de la Constitución de 1991 empezó el proceso descentralizador con un marco bastante sesgado hacia la transferencia de competencias y recursos fiscales al nivel municipal durante el gobierno del presidente Gaviria. A continuación en el Cuadro 1 se presenta un resumen de los avances del proceso descentralizador en Colombia y Venezuela. Es de destacar que ambos países han transferido competencias de forma similar hacia los departamentos/estados y municipios.

Cuadro 1 - Avances del proceso de descentralización en Colombia y Venezuela

Descripción

Funciones

Atribuciones en Servicios

\section{Poder Regional: Departamento / Estado}

\section{Colombia}

\section{Venezuela}

- Planificar y promover el desarrollo económico y Social en el territorio con- - Organización de sus municipios y decertadamente con los municipios para más entidades locales y su división polícomplementar labores de intermedi- tico territorial ación entre la nación y los municipios. - Intermediario entre la nación y el mu- Apoyo financiero y crediticio a los mu- nicipio. nicipios

- garantizar la prestación de servicios.

Creación, régimen y organización de los servicios públicos estadales, ejecución, conservación, administración y aprovechamiento de las vías terrestres estadales. trativo.

- Turismo, transporte, ambiente, obras públicas, vías de comunicación y desarrollo de sus zonas de frontera
- Conservación, administración y aprovechamiento de carreteras nacionales, puertos y aeropuertos en coordinación con el ejecutivo nacional. 


\section{Cuadro 1 - Avances del proceso de descentralización en Colombia y Venezuela}

\section{Poder Municipal}

\section{Descripción}

Colombia

\section{Venezuela}

- Servicios de agua potable, electricidad y gas doméstico; de alumbrado públi- Servicios domiciliarios de acueducto, alcantarillado, aseo, energía eléctrica y telefonía pública conmutada

- Salud, Educación, agua potable y saneamiento básico, vivienda, subsidios a población de menos recursos

- Construir obras para el progreso local, ordenar el desarrollo de su territorio, promover participación comunitaria, el mejoramiento social y cultural de sus habitantes.

- Primera instancia en delitos de hurto simple, violación de la habitación, ejercicio arbitrario de las propias razones, permanencia ilícita en habitación ajena, lesiones personales dolosas entre otras

- Ciertas infracciones de tránsito

- Conciliar controversias de carácter patrimonial susceptibles de ser reclamadas en lo contencioso administrativo. co, alcantarillado, canalización y disposición de aguas servidas, de mataderos, cementerios, servicios funerarios, abastecimiento y mercados.

- Salud y atención primaria en educación, actividades e instalaciones deportivas y culturales.

- Ordenación territorial y urbanística vivienda de interés social, turismo local, arquitectura civil, vialidad urbana, circulación y ordenación del tránsito de vehículos y personas en las vías municipales y los servicios de transporte urbano.

- La justicia de Paz, la atención social sobre la violencia contra la mujer y la familia, prevención y protección vecinal, policía municipal y vigilancia, entre otros.

FUENTE: República de Colombia, 1991;

República Bolivariana de Venezuela, 1999, 2005.

La descentralización político-administrativa en Colombia y Venezuela se venía gestando desde décadas atrás aunque se plasma efectivamente, en las Constituciones de 1991 y 1999 respectivamente. En ambos países se acepta que el municipio es la mínima unidad de gestión político-administrativa y depositario directo del proceso de descentralización. Según resumen detallado del Cuadro 1, los municipios y los gobiernos regionales tienen en principio atribuciones relativamente similares, por lo que se destaca la homogeneidad comparativa de las funciones de los entes infranacionales. 
A pesar de las similitudes, con el proceso de Reformas del Estado que condujeron a la elaboración de nuevas Constituciones Nacionales, la organización territorial colombiana permite al municipio, al igual que a los departamentos, ubicados en zonas fronterizas adelantar directamente con la "entidad territorial limítrofe del país vecino, de igual nivel, programas de cooperación e integración dirigidos a fomentar el desarrollo comunitario, la prestación de servicios públicos y la preservación del ambiente” (Art. 289) con lo que se otorgan ciertas competencias en política exterior a las unidades infranacionales. En Venezuela tal posibilidad no existe (ver Cuadro 2). Con ello las opciones de los gobiernos regionales y municipales para avanzar coordinadamente en aspectos que son de su competencias quedan bastante comprometidas a pesar que cada país proclama en sus constituciones que la integración Latinoamericana es parte fundamental de sus políticas exteriores. Así, las diferencias constitucionales limitan el desarrollo y ejercicio real de la supra e infranacionalidad en esta región debido a que ello inhibe la necesaria homogeneidad normativa que se requiere para coordinar las políticas propias de procesos de integración más avanzados.

\section{La supranacionalidad e infranacionalidad andina y su aplicación en Colombia y Venezuela}

La CAN ha logrado consolidar una red normativa bastante elaborada, siendo la de integración física una de ellas. La integración física se propone contribuir a una mayor homogeneidad económica entre los países miembros y entre sus regiones. $\mathrm{Al}$ respecto, al igual que todo el proceso de integración, la integración física ha pasado por distintas etapas, de las cuales tres son bastante visibles. En la primera, vigente a partir de 1969, se limitó a los proyectos de integración vial por carreteras y fue poco lo que se avanzó en esta materia pues muchos de los proyectos de infraestructura han dependido y dependen de la continuidad de visiones respecto al desarrollo que ostente cada gobierno, así como a visiones compartidas con los países socios. La segunda se inicia hacía finales de los ochenta con la Declaración de Galápagos (1989) con la progresiva simplificación y armonización de procedimientos aduaneros y migratorios. A partir de entonces, se reconsideran las ideas previas y se incorporan los temas de desarrollo regional y fronterizo como 
preocupación común; en parte debido a la escasa integración, marginalidad y limitados niveles de desarrollo de las fronteras y en parte debido a las agudas manifestaciones en las fronteras de las crisis de seguridad interna de algunos países. La manifestación del cambio en la política de fronteras en la CAN sólo logra consolidarse después y en 1999 la Comisión aprueba la Decisión 549 relativa a la Política Comunitaria para la Integración y el Desarrollo Fronterizo. Seguidamente, en el 2001 se aprueba la Decisión 501 sobre las Zonas de Integración Fronteriza (ZIF) en la comunidad andina mediante la cual autoriza el establecimiento de ZIFs entre los países miembros o con terceros países con el fin de promover el desarrollo en las regiones de frontera, las cuales se han mantenido marginadas en los niveles de desarrollo.

La tercera etapa es visible a partir del 2000 ya que separa lo estrictamente fronterizo de la integración física e incorpora una nueva forma de percibir el desarrollo andino. De esta forma hay mayor interés por las marcadas desigualdades en el desarrollo tanto entre países como entre regiones. Se elaboran criterios básicos de medición de los niveles de desarrollo a escala comunitaria para que, luego de un período de revisión, se pueda evaluar con mayor precisión los niveles de desarrollo a nivel andino antes que nacionalmente. Se espera que de los resultados de tales evaluaciones se elaboren políticas comunes de desarrollo regional. En este sentido, en el 2002 se aprueba la Decisión 534 sobre la Nomenclatura de Unidades Territoriales Estadísticas (NUTE) donde se homogeniza los tratamientos en términos estadísticos a las distintas áreas de los países miembros y más recientemente, en el 2004 se aprobó la Decisión 585 mediante la cual se crea el Consejo Consultivo de Autoridades Municipales para adelantar la cooperación basada en la ejecución de políticas comunitarias andinas en apoyo al desarrollo regional y la descentralización (COMUNIDAD ANDINA, marzo 2006). No obstante lo anterior hay un aparente retorno al privilegio de los proyectos de infraestructura como motores del desarrollo suramericano y en este sentido la estrategia de la Iniciativa para la Integración de la Infraestructura Regional Suramericana (IIRSA) es un ejemplo de ello.

$\mathrm{El}$ avance de estrategias comunes de desarrollo infranacional, fronterizo y binacional, desde los organismos Comunitarios, a pesar de haber sido propuestos y aprobados por los gobiernos nacionales, son improbables o poco operativas si los mismos gobiernos no asumen la disposición de operacionalizar 
las mencionadas Decisiones Comunitarias pues no se disponen de recursos comunitarios para ejecutarlas. El proceso de descentralización en estos países es complicado para las opciones de desarrollo local si se analiza conjuntamente con la dificultad propia de "planificar y ejecutar el desarrollo de manera conjunta, compartida y coordinada” (Decisión 501) entre los municipios o departamentos o estados de Colombia y Venezuela que constituyen la ZIF Norte de Santander - Táchira ${ }^{1}$, pues las Constituciones Nacionales no otorgan facultades similares de asociación con municipios o regiones del otro país (ver Cuadro 2).

En integración, los dos países eran, hasta el 20 de abril de 2006, momento en que Venezuela denuncia el Acuerdo de Cartagena, Colombia y Venezuela eran los pilares fundamentales de la supranacionalidad andina. En el 2001 aprobaron la Decisión 501 que establece la definición y la creación de ZIFs en la CAN (CAN, Decisión 501). Sin embargo, a pesar del avance de la integración en lo normativo hasta marzo de 2006, Colombia y Venezuela eran el único par de países que no la habían creado; situación que empezaba a resolverse con el intercambio de notas reversales creó la ZIF Norte de Santander - Táchira en la frontera y que quedó pendiente al producirse la denuncia del Acuerdo por Venezuela pues aún no se habían enviado las notas respectivas a la Secretaría General de la CAN para su ratificación y publicación en la Gaceta Oficial del Acuerdo.

La creación de la ZIF siguiendo los lineamientos de la Decisión 501 y el retiro de Venezuela de la CAN han colocado en incertidumbre el futuro desarrollo de la esta ZIF. La Decisión 501 establece que la creación es decisión bilateral de los gobiernos y que "de considerarlo conveniente", podrán establecerlas con terceros países (art.2). Es posible que siendo la ZIF una realidad jurídica binacional y de mantenerse vigentes los principios que inspiraron su creación aún quede la posibilidad de continuar con su implementación siguiendo los lineamientos de la 501 pero bajo un acuerdo binacional.

\footnotetext{
${ }^{1}$ Los municipios que constituyen la ZIF son: 12 por el Departamento de Norte de Santander (Colombia): Cúcuta, Chinacota, El Zulia, Herrán, Los Patios, Pamplona, Pamplinita, Puerto Santander, Regonvalia, San Cayetano, Toledo y Villa del Rosario y 15 por el estado Táchira: Ayacucho, Bolívar, Cárdenas, Córdoba, Fernández Feo, García de Hevia, Independencia, Junín, Libertad, Libertador, Lobatera, Pedro María Ureña, rafael Urdaneta y San Cristóbal, Tórbes. Nota diplomática enviada por el Ministro de Relaciones Exteriores (E) de Venezuela, dr. Pável Rondón a su homólogo colombiano Dra. Carolina Barco el 17 de enero de 2006. La nota fue respondida en marzo de 2006.
} 


\section{Cuadro 2 - Atribuciones en materia de relaciones internacionales relacionadas con la descentralización en la CAN y en Colombia - Venezuela}

Comunidad Andina

Tratado de Tribunal Andino de Justicia. Art. 3: Las Decisiones son directamente aplicables a los países miembros a partir de la fecha de su publicación en Gaceta Oficial del Acuerdo. Art. 4. Los países miembros están obligados a adoptar las medidas que sean necesarias para asegurar el cumplimiento de las normas que conforman en ordenamiento jurídico de la CAN.
El Estado promoverá la integración económica, social y política con las demás naciones y especialmente con los demás países de América Latina y el Caribe mediante la celebración de Tratados que creen organismos supranacionales.

Los Tratados deben ser aprobados por el Congreso

República Unitaria con autonomía de sus entidades territoriales.

Organización Territorial: Departamentos, distritos, municipios y territorios indígenas. Opción para regiones y Provincias

Decisión 534 Nomenclatura de Unidades Territoriales Estadísticas (NUTE) donde se homogeniza los tratamientos en términos estadísticos a las distintas áreas delos países miembros
Las competencias atribuidas a los distintos niveles Competencias atribuidas a territoriales serán ejercidas los poderes públicos bien deconforme a los principios de finidas y no hay mención a coordinación, concurrencia coordinación, concurrencia y subsidiariedad en los tér- o subsidiariedad en la C.N minos que establezca la Ley. (1999)

Art. 288. C.N (1991)
Art. 153 de la Constitución se podrá atribuir a autoridades supranacionales, mediante Tratados, el ejercicio de competencias necesarias para llevar a cabo procesos de integración.

Las Normas que se adopten en el marco de los Acuerdos de integración serán parte integrante del ordenamiento legal vigente y de aplicación directa y preferente a la legislación interna.

Los Tratados celebrados por la República deben ser aprobados por la Asamblea Nacional antes de su ratificación por el Presidente

Estado Federal Descentralizado.

Organización Territorial: estados, distrito capital, entidades federales y los territorios federales. El territorio se organiza en Municipios. 
Cuadro 2 - Atribuciones en materia de relaciones internacionales relacionadas con la descentralización en la CAN y en Colombia - Venezuela

\section{Comunidad Andina}

Decisión 585 Consejo Consultivo de Autoridades Municipales para adelantar la El Municipio es la entidad cooperación basada en la fundamental de la división ejecución de políticas comu- político administrativa del nitarias andinas en apoyo al Estado

desarrollo regional y la descentralización.

Decisión 459 crea la Política de Integración y Desarrollo Fronterizo y establece que deben crearse Zonas de Integración Fronteriza (ZIFs)

Decisión 501 establece los lineamientos, principios y objetivos para la creación de ZIFs entre dos o más países en las fronteras comunes de los países miembros
Los Departamentos y municipios ubicados en las zonas fronterizas podrán adelantar directamente con la entidad territorial limítrofe del vecino país, de igual nivel, programas de cooperación e integración dirigidos a fomentar el desarrollo comunitario, la prestación de servicios públicos y la preservación del medio ambiente (art. 289)

\section{Colombia}

Venezuela

Municipio Unidad Político

Primaria de la organización nacional, gozan de personalidad jurídica y autonomía dentro de los límites de la Constitución Nacional

FUENTE: Comunidad Andina, 2006; República de Colombia, 1991; República

Bolivariana de Venezuela, 1999.

\section{Las relaciones y percepciones binacionales colombo- venezolanas}

Las relaciones entre Colombia y Venezuela han estado signadas por la competencia y el recelo propio de dos países adyacentes, que a lo largo de su historia han mostrado diferencias en sus liderazgos y formas de concebir su presente y futuro así como en las expectativas del uno respecto al otro.

En lo relativo al liderazgo se destaca que los constructores de naciones y de la historia se encargaron de marcar diferencias sustanciales entre los héroes de la independencia. Para la historiografía colombiana y venezolana Santander y Páez fueron dos líderes que antepusieron sus "apetencias personales y sus mezquinas ambiciones" (Quintero, 2005) ante el sueño de Bolívar de construir a "Colombia la Grande". Parte de esos "oscuros intereses de los forjadores" de lo que resultó ser Colombia y Venezuela, se encuentran en las 
diferencias entre Bogotá y Caracas pues Bogotá manifestaba la experiencia administrativa y el orgullo de haber sido la sede del Virreinato mientras que Caracas lo era de una Capitanía General y por tanto de menor rango administrativo y militar.

Luego de desmembrada Colombia la Grande, se inicia el proceso de delimitación territorial que partió del principio del Uti Possidetis Jure de 1810 y que bien pronto demostró ser insuficiente. A partir de 1830 hasta la actualidad, según lo muestran los trabajos de Salazar (1983) y Montero (1997) los dos países han elaborado una serie de imágenes negativas respecto al país vecino. Así para Venezuela y los venezolanos Colombia es un país agresor que se ha valido de la buena voluntad de Venezuela para apoderarse de gran parte del territorio nacional (ASCANIO, NAVAS et al., 1972) especialmente durante la negociación conducente al Laudo Español de 1891 cuando se estima se perdió gran parte de los llanos y costas de la Guajira que habrían impedido llegar al problema actual de delimitación de áreas marinas y submarinas. Igualmente para Colombia y los colombianos, Venezuela se niega a delimitar las áreas marinas y submarinas en el "Golfo de Venezuela”. (Ramírez y Hernández, 2003) mientras que ejerce posesión y soberanía total sobre el mismo. El Cuadro 3, elaborado inicialmente por Ramírez y Hernández (2003) da cuenta del largo período de negociaciones entre Colombia y Venezuela respecto a la delimitación territorial.

\section{Cuadro 3 - Negociaciones limítrofes de Colombia y Venezuela}

Fecha

1833

1881

1891

1916 Laudo Suizo

1939

1941
Evento

Pombo-Michelena de amistad, comer- No entró en Vigencia. Aceptado por cio, navegación y límites Solicitud de arbitraje español para superar diferencias limítrofes

Laudo español

Tratado de no agresión, conciliación, arbitraje y arreglo judicial

Tratado de límites y navegación por los

Ríos Comunes y de solución pacífica de controversias.

\section{Proceso o resultado}

Colombia, negado por Venezuela.

Acuerdo

Aceptado con renuencia por Venezuela. Diferencias sobre su ejecución

Puso en marcha comisión de demarcación

Acuerdo toriales en los límites terrestres
Se declara finalizadas las disputas terri- 


\section{Cuadro 3 - Negociaciones limítrofes de Colombia y Venezuela}

Fecha

Evento

Estudio Boggs encomendado por Co- Malestar en Venezuela y reclamación

1951 lombia sobre delimitación en el Golfo de Venezuela

1969 Declaración de Sochagota

1970 Acuerdo de primer modus opperandi 5 rondas de negociaciones en Roma, López Michelsen de Colombia pro-

1970- pone delimitación proporcional a los 1977 perímetros de cada país, López (Colombia) y Pérez (Venezuela) acuerdan formulas a consultar

1978

Acuerdo de segundo modus operandi y se llega a la Hipótesis de Caraballeda

Decreto 1436 del gobierno colombiano sobre medición del mar territorial y de la ZEE a partir de líneas de base recta en el Golfo. Mapas colombianos con los Monjes y demanda de la nota de 1952 sobre los Monjes

Declaración del Arauca entre Jaime Recomienda formular un nuevo mo-

1986 Lusinchi (Venezuela) y Belisario Be- dus operandi para reanudar las negotancour

Colombia propone acudir al Tratado Venezuela rechaza la propuesta e insisde 1939 y nombra sus comisionados. te en dialogo directo

Corbeta Caldas (colombiana) entra en Venezuela responde enviando naves de

1987 las aguas en disputa y bajo el control guerra al Golfo y exige el retiro inmede Venezuela

\section{diato.}

Declaración de la nulidad de la Nota

1992

Decisión del Consejo de Estado colombiano

Las Comisiones Negociadoras (CO-

2006 NEG) instaladas en 1990 se encuen- Paralización tensa de la reclamación. tran trabajando a muy bajo perfil. 
Adicionalmente, los gobiernos de Colombia y Venezuela no parecen tener percepciones similares respecto al futuro compartido. Tal es el caso del régimen socioeconómico y la función del Estado en la economía: la Constitución venezolana señala que el mismo se fundamenta en "los principios de justicia social, democratización, eficiencia y libre competencia”, entre otros y además mantiene que el "Estado conjuntamente con la iniciativa privada promoverá el desarrollo armónico de la economía nacional”(Art. 299) mientras que en el artículo 301 afirma que el "Estado se reserva el uso de la política comercial para defender las actividades económicas de las empresas públicas y privadas". Por su parte, la constitución colombiana señala, en su artículo 333, que la "actividad económica y la iniciativa privada son libres dentro de los límites del bien común” mientras que en el artículo 334 establece que el Estado "intervendrá para racionalizar la economía con el fin de conseguir el mejoramiento de la calidad de vida de los habitantes, la distribución equitativa de las oportunidades y los beneficios del desarrollo y la preservación de un ambiente sano". Así, aunque parecieran diferencias de redacción o matiz, las visiones del Estado respecto a la dirección socioeconómica apuntan en direcciones diferentes pues Venezuela otorga un papel protagónico al Estado en la economía mientras que Colombia parece colocar al Estado en una función más reguladora. Ello significa dos visiones distintas de Estado y de su funciones respecto a la pobación y el territorio. Los propósitos, objetivos y metas comunes son necesarios para adelantar con éxito relaciones binacionales y experiencias de integración, incluyendo las translimítrofes (HAAS, 1967; LINDBERG, 1994; FRAMBES BUXEDA, 1994).

La política exterior ha sido otro de los ámbitos en los cuales Colombia y Venezuela han demostrado sus recelos y discrepancias. Tradicionalmente han participando en las mismas organizaciones internacionales a pesar que las posiciones coincidentes han sido escasas. Estados Unidos ha sido el país con el cual han mostrado mayores diferencias y a partir de allí se enlaza y justifica una serie de divergencias. Colombia ha tendido tradicionalmente a tener una posición más cercana a los Estados Unidos en materia de política exterior (RAMÍREZ, ROMERO, SANJUÁN, 2005; ARDILA, CARDONA, TICKNER, 2002) mientras que Venezuela ha optado por mantener una de neutralidad relativa, la cual puede tal vez explicarse, actualmente, por 
el recurso energético asociado al petróleo aunque desde la independencia Simón Bolívar advertía sobre los peligros que Estados Unidos representaba o podría representar para la unidad que el planteaba. Por ejemplo, en los años ochenta Colombia respaldo a Estados Unidos y a Gran Bretaña en el conflicto bélico de las Malvinas mientras que Venezuela hizo lo propio con Argentina. Recientemente, Colombia y Venezuela se han aislado por el apoyo que Colombia ha manifestado respecto al ALCA y a la firma reciente del Tratado de Libre Comercio con Estados Unidos, el cual es rechazado de manera pública por el gobierno venezolano de Hugo Chávez (www.elnacional.com; consulta el 21 de abril de 2006, A-1). De la misma forma Colombia y Venezuela tienen posiciones encontradas respecto a la guerra en Irak pues Colombia apoya abierta y oficialmente a Estados Unidos mientras que Venezuela lo opone de la misma forma. Tal vez, una de las pocas iniciativas de integración donde estos dos países se habían acercado más era la CAN y ello muy probablemente se debía, en algunos momentos a la coincidencia de visiones respecto a la integración y al interés de atender la desigualdad, la pobreza y lo fronterizo con una visión más global y más allá de lo inminentemente limítrofe y nacional.

Sin embargo a pesar de la incidencia de las divergencias, la dinámica fronteriza de ambos países ha incidido notablemente para que, salvo contadas excepciones como lo fue el caso del conflicto de transporte de $1999^{2}$, se decida por disminuir las diferencias y retornar a la cooperación e integración. Ello se evidencia en el Cuadro 4 donde se presenta una relación de actuaciones en donde lo fronterizo ha sido parte significativa de las relaciones bilaterales. Es de esperar que el retiro de Venezuela de la CAN y el distanciamiento entre los gobiernos de Colombia y Venezuela produzcan respuestas en la frontera que permitan la continuación de los avances en materia de integración fronteriza. $\mathrm{Al}$ respecto el pronunciamiento de los sectores productivos agrupados en Fedecámaras en Venezuela y en

\footnotetext{
${ }^{2}$ En 1999 los transportistas de mercancías por carretera del estado Táchira (Venezuela) hicieron una huelga que paralizó todo el transporte entre Venezuela y Colombia y afectó el libre movimiento de personas y bienes por aproximadamente una semana en protesta por la Decisión 399 que autorizaba el libre tránsito de vehículos ed carga pesada en los países miembros de la CAN. Colombia y Venezuela estaban ejecutando la Decisión y después de un año de reclamos, los transportistas de la frontera acudieron a esta medida de fuerza que condujo a que el gobierno venezolano suspendiera la aplicación de la medida.
} 
la Cámara de Comercio colombo-venezolana (CAVECOL) llaman a los gobiernos a buscar salidas que no afecten la dinámica binacional y el respeto del acervo comunitario en Venezuela (La Nación, mayo-junio, 2006). De la misma forma el Consejo Consultivo Empresarial de la CAN elabora una Declaración en la que lamenta el retiro y llama al dialogo entre las partes (Colombia Internacional, www.colombiainternacioal.org; consulta en línea 30/06/2006) Y por su parte el Consejo Consultivo Laboral luego de diversas discusiones acordaron finalmente, en septiembre de 2006, seguir trabajando con la centrales sindicales venezolanas en calidad de organizaciones fraternas a las cuales se les confiere el rango de observadoras en las reuniones ordinarias (Consejo Consultivo Laboral Andino, www.ccla.org.pe; consulta en línea 30/09/2006). 
Cuadro 4 - Eventos en los cuales las dinámicas fronterizas han formado parte de las relaciones bilaterales colombo-venezolanas

Fecha

Evento

Resultado

Bajo arancel, navegación libre por los

1842

Convenio de amistad, comercio y navegación

1925 Convenio de Cooperación

Documento de la Sociedad Binacional Solicitan a los gobiernos dinamizar las del Táchira y del Norte de Santander

1942 Estatuto Fronterizo

1959 Tratado de Tonchalá

Acta de San Cristóbal

Acuerdo Comercial y de Desarrollo Económico

1963

1965 Comisión de Integración Fronteriza

1969 Declaración de Sochagota ríos comunes, igualdad de trato impositivo. La separación no debería afectar las poblaciones fronterizas.

Construcción de Puente Internacional relaciones económicas bilaterales

A raíz de la firma del Tratado de límites se insiste en mantener la dinámica fronteriza en Táchira- Norte de Santander. El Estatuto regula flujos poblacionales, ambiente y seguridad judicial

Profundización del Estatuto Fronterizo en educación, migraciones, salud.

Evaluación y solución de problemas comunes, realización de programas conjuntos en la zona fronteriza, aprovechamiento de recursos naturales compartidos y de comercio.

Discusión sobre mercado común e integración económica, aprovechamiento de la herencia cultural y tradición compartida, programas sociales comunes y Comité mixto de expertos sociales y del sector privado.

Primer órgano de vecindad

Impulso a Proyectos binacionales: sanitario y Petroquímico, construcción de puentes Ureña, San Antonio, Arauca; estudios sobre situación social, indígenas en la zona de frontera; desarrollo de cuencas hidrográficas: río Paraguachón, navegación en el Orinoco; interconexión eléctrica La Fría y Norte de Santander; vías Zulia-Cesar, Guasdualito-Arauca. 
Cuadro 4 - Eventos en los cuales las dinámicas fronterizas han formado parte de las relaciones bilaterales colombo-venezolanas

\begin{tabular}{|c|c|c|}
\hline Fecha & Evento & Resultado \\
\hline 1987 & $\begin{array}{l}\text { Creación Asamblea Regional } \\
\text { Fronteriza Norte de Santander. } \\
\text { Táchira. Reuniones periódicas de } \\
\text { Gobernadores de Táchira y Norte de } \\
\text { Santander }\end{array}$ & $\begin{array}{l}\text { Constituida por los legisladores de las } \\
\text { dos entidades. } \\
\text { Gobernadores de las dos entidades } \\
\text { regionales } \\
\text { Finalmente se eliminan. }\end{array}$ \\
\hline 1989 & $\begin{array}{l}\text { Reunión Presidencial Pérez (Vzla) } \\
\text { - Barco (Col); } \\
\text { Declaración de Ureña }\end{array}$ & $\begin{array}{l}\text { Conformar comisiones fronterizas. } \\
\text { Comisiones Presidenciales de Asuntos } \\
\text { Fronterizos (COPAF). Lista de temas } \\
\text { a tratar: tránsito de personas, traba- } \\
\text { jadores indocumentados, indígenas, } \\
\text { explotación abusiva de los recursos na- } \\
\text { turales, orden público, inseguridad y } \\
\text { desarrollo científico y tecnológico. }\end{array}$ \\
\hline 1994 & $\begin{array}{l}\text { Acta de Casa Amarilla. Caldera (Vzla) } \\
\text { - Gaviria (Col) }\end{array}$ & $\begin{array}{l}\text { Establecer un comité fronterizo bina- } \\
\text { cional con autoridades locales y socie- } \\
\text { dad civil fronteriza. }\end{array}$ \\
\hline 1999 & $\begin{array}{l}\text { Paralización del transporte de mercan- } \\
\text { cía pesada }\end{array}$ & $\begin{array}{l}\text { Reacción de los transportistas de fron- } \\
\text { tera de la frontera por su desplaza- } \\
\text { miento del transporte binacional al } \\
\text { regularizarse el libre tránsito de mer- } \\
\text { cancías por transportistas acreditados } \\
\text { según normas de Decisión } 399 \text {. }\end{array}$ \\
\hline $\begin{array}{l}2000- \\
\text { actualidad }\end{array}$ & $\begin{array}{l}\text { Reuniones de los gobernadores de Tá- } \\
\text { chira y Norte de Santander }\end{array}$ & $\begin{array}{l}\text { Buscar acordar salidas conjuntas a las } \\
\text { relaciones cotidianas de convivencia } \\
\text { fronteriza }\end{array}$ \\
\hline 2004 & $\begin{array}{l}\text { Acta compromiso gobernadores de } \\
\text { Norte de Santander - Táchira }\end{array}$ & $\begin{array}{l}\text { Ratifican decisión de respaldar estu- } \\
\text { dio conducente a la creación de la ZIF } \\
\text { Norte de Santander - Táchira }\end{array}$ \\
\hline 2004 & Incidente con Guerrillero Granda & $\begin{array}{l}\text { Paralizó la dinámica en la frontera du- } \\
\text { rante días. Presión de las poblaciones } \\
\text { incidió para retorno a la normalidad. }\end{array}$ \\
\hline
\end{tabular}

FUENTE: Reelaboración a partir de cuadros elaborados por Ramírez, Hernández, 2003; Bustamante, Sierra et al., 2005

Lo significativo de este recuento de acciones es el significativo papel que han desempeñado las poblaciones fronterizas de Norte de Santander - Táchira por disminuir las tensiones entre los gobiernos y lograr que las mismas se transformaran, al menos, en actos "protocolares" de amistad y 
cooperación. Tal es el caso de la Asamblea Regional Fronteriza (ARF) creada en 1987 que, a pesar de no contar con el respaldo de los gobiernos nacionales, vino a disminuir las tensiones en un período casi-bélico derivado de la incursión de la Corbeta Caldas en las Aguas del Golfo de Venezuela (BUSTAMANTE, SIERRA et al., 2005). LA ARF fue más tarde eliminada aunque se estima que fue el preámbulo a las Comisiones Presidenciales de Asuntos Fronterizos (COPAFs). Más recientemente, Norte de Santander y Táchira siguen presionando a los gobiernos centrales para la creación definitiva y operacionalización de la ZIF.

Aunque parezca paradójico, la participación real de las poblaciones fronterizas en el proceso de integración también ha sido visible para disminuir u obstruir el ritmo del proceso de integración regional y colombo-venezolano, como ocurrió en 1999 cuando se sintieron excluidas del proceso de toma de decisiones sobre asuntos que les afectaban directamente sus condiciones de vida. Lo que no se ha analizado con precisión es que tanto se debe al compromiso con la integración o a una respuesta a los cambios que la misma introduce en la cotidianidad y en los planes y visiones locales.

Estos elementos de la historia colombo-venezolana han generado un cuadro donde la supranacionalidad no tiene un nivel de aceptación o consolidación institucional en los órganos de poder del Estado. El Estadonación sigue siendo el centro de poder y depositario principal de las lealtades de la población si se compara con otras instancias de poder supra o subnacional como serían los poderes municipales y regionales. Paradójicamente al mismo tiempo, los poderes y actores regionales y locales de las fronteras en algunos momentos han logrado imponer sus agendas de cotidianidad y convivencia. La incertidumbre es hasta dónde pueden la CAN y las zonas de frontera modificar las agendas de los gobiernos centrales. Pero hasta ahora ha sido poco lo que han avanzado en esa dirección.

\section{La supranacionalidad e infranacionalidad en la integración andina. Sus manifestaciones en la frontera Norte de Santander (Colombia) - Táchira (Venezuela)}

En los apartados anteriores hemos mostrado que los avances en la integración y en el proceso de integración andino, en particular; al igual 
que la descentralización infranacional en Colombia y Venezuela no han avanzado ni suficientemente ni en direcciones similares en cuanto a permitir la cooperación o integración transfronteriza en los espacios fronterizos comunes. Sobre lo infranacional, Colombia y Venezuela habían acordado mantener el control de la ejecución de las Decisiones y la CAN se limitaba a recordar o hacer reuniones en las cuales se intentaba evaluar o recordar a los países los compromisos adquiridos de común acuerdo. La CAN creaba propuestas que una vez aprobadas por la Comisión pasaban de nuevo el poder a los gobiernos centrales para su desarrollo y ejecución. Nacionalmente, parecen haber adelantado la descentralización en términos verticales de manera similar al transferir competencias similares a los gobiernos regionales y municipales. La diferencia está en el otorgamiento de competencias de asociación que otorga Colombia a los departamentos y municipios con sus homólogos del vecino país ya que Venezuela no lo permite. Tal diferencia se justifica, en parte, en las visiones que tiene cada país sobre la concepción del Estado, de los espacios de poder, el recelo respecto al otro, que producen como resultado dos países vecinos que carecen de objetivos comunes plasmados en sus Constituciones, en la distribución del poder en las entidades territoriales y en las políticas domésticas y exteriores. Así las manifestaciones de supranacionalidad en el sentido de otorgamiento de competencias a órganos supranacionales para actuar en los ámbitos locales de los países o, en sentido contrario, de brindar posibilidades a las comunidades o municipalidades para actuar en los órganos comunitarios son inexistentes.

Según lo observado en el Cuadro resumen 2, Colombia se define como "República Unitaria con autonomía de sus entidades territoriales" y Venezuela lo hace como un "Estado Federal descentralizado". Tales definiciones sugieren que Venezuela otorga mayor autonomía a las entidades infranacionales, pero al revisar las competencias y libertades transferidas, Colombia parece ser más federal y menos centralista o unitaria ya que en el tema de las competencias del poder de las fronteras, la Constitución les permite ejercer ciertas y limitadas funciones en el área de relaciones internacionales pues no sólo se definen las atribucuiones de los poderes sino que además incluye los conceptos de coordinación, concurrencia y subsidiariedad, principios que no aparecen en la venezolana. 
Para ejemplificar las resistencias de los gobiernos centrales a ceder poder a los órganos supra e infranacionales en materias que son consideradas de su competencia absoluta se presenta el proceso seguido por la frontera de Táchira para solicitar la incorporación de cierta competencia en relaciones internacionales a los estados y municipios fronterizos durante el proceso que condujo a la elaboración y aprobación de la nueva constitución nacional debido a que la Constitución vigente hasta el momento (1961) no lo permitía y la colombiana si lo permitía desde 1991 .

Habiendo pasado Colombia por un proceso constituyentista previamente a Venezuela, la experiencia colombiana fue referencia obligada para Venezuela. En Colombia las competencias de los poderes regionales y locales de frontera, en materia de relaciones internacionales de vecindad, ya eran norma y lo lógico era esperar que algo similar ocurriera en Venezuela, pero ello no fue posible a pesar que constituyentistas colombianos fueron invitados a asesorar el proceso venezolano y pese a que los habitantes de la frontera reclamaron la inclusión de un artículo similar al 289 de la Constitución de Colombia en la Constitución Venezolana. En un Documento elaborado por el Centro de Estudios de Fronteras e Integración (CEFI) de la Universidad de Los Andes en Táchira, y entregado a los Constitucionalistas electos por el estado Táchira (CEFI, 1999) se recogen las distintas opiniones obtenidas en una serie de foros sobre "la Frontera y la Constituyente" y en éste se señala que los actores sociales activos del estado y de la frontera consideraban prioritario para el desarrollo futuro de la frontera común y de la integración andina, la inclusión de un artículo que al igual que el 289 de la Constitución de Colombia, otorgara potestades similares a los gobiernos regionales y municipales de Venezuela en materia de fronteras. En los foros los participantes destacaban la influencia poco estimulante de las políticas de los gobiernos centrales hacia las fronteras, por lo que se tornaba significativa la obtención de cierto margen de autonomía local. Contrariamente a lo solicitado de manera clara, los constituyentistas del estado Táchira no lograron el cometido y la Constitución venezolana otorga todo el poder en materia de fronteras y de relaciones internacionales al gobierno central. Al indagar las posibles razones y causas que impidieron cumplir con tal petición, de manera muy somera y extraoficialmente se ha podido oír, una queja respecto al peso del centralismo 
y del predominio de concepciones muy cerradas respecto a Colombia de parte de los demás constituyentistas y de los órganos de seguridad del Estado que participaban en las reuniones conducentes a la redacción del texto final de la Constitución de 1999.

El peso del centralismo y de concepciones cerradas respecto a Colombia puede solapar o encubrir el tradicional malestar, recelo y desconfianza que han estado presentes a lo largo de la historia de estas dos naciones, según se ilustró en la parte II de este trabajo.

Las consecuencias de estas actitudes y procedimientos ciertamente seguirán siendo óbice para el avance de la integración andina y latinoamericana pero fundamentalmente para el desarrollo de la frontera común de estos dos países. La frontera de Norte de Santander - Táchira, a pesar su aparente dinámica, no puede evadir la suerte de las fronteras y muy poco pueden construir en términos de desarrollo regional siguiendo los nuevas tendencias de la Geografía Económica en términos de una ventajosa ubicación territorial y de unos recursos naturales y humanos significativos (BUSTAMANTE, SIERRA et al., 2005).

En síntesis, la frontera de Norte de Santander - Táchira, a pesar de ser la más dinámica de la frontera colombo-venezolana y de Suramérica poco ha logrado avanzar producto o derivado de los avances la supranacionalidad y la infranacionalidad. Su dinámica poblacional ha impedido la imposición definitiva de las agendas centralistas y de separación y en muchos casos ha logrado disminuir las tensiones entre los países. También es de destacar que ciertas decisiones sobre desarrollo regional fronterizo en la CAN se debieron a las presiones y poder de "lobby" que han tenido los actores locales y regionales en los escenarios nacional y andino. 


\section{Epilogo $^{3}$}

El trabajo estuvo orientado a mostrar que la integración andina, al igual que la descentralización infranacional en Colombia y Venezuela no habían avanzado más allá de la creación de normas ni en direcciones similares para facilitar la cooperación o integración en los espacios fronterizos comunes. La integración andina no se ha profundizado lo necesario para retar el poder de los gobiernos centrales o los Estado-nación los cuales continúan siendo los depositarios principales de las lealtades de sus poblaciones. Ello, aunado a los recelos respecto al otro, hacen bastante lento el proceso de integración andino y transfronterizo. La Denuncia del Acuerdo de Cartagena por parte de Venezuela no sólo reforzó esta percepción sino que mostró que tan frágiles son los logros y que tan profundas y poderosas pueden ser las diferencias cuando las visiones compartidas a futuro están ausentes. La suposición del valor del acervo comunitario para generar ganancias y compromisos duraderos no es suficiente para un país o un gobierno cuando percibe que los fundamentos que hicieron posible tal Acuerdo chocan con principios que también son fundamentales a su propia estrategia de gobierno.

De la misma forma, en la descentralización infranacional se ha avanzado mayoritariamente en el ámbito normativo o jurídico pero en la práctica los desarrollos son más lentos. Venezuela parece estar reconcentrando el poder y con las más recientes leyes de los Concejos Comunales (ASAMBLEA

\footnotetext{
${ }^{3}$ La investigación y propuesta de este trabajo se realizó en los meses previos a la denuncia del Acuerdo de Cartagena por parte de Venezuela en abril de 2006 y aunque habían declaraciones y reconocimientos de parte de los voceros de los miembros de la CAN y de los países miembros de la existencia de problemas que colocaban a la integración andina en una situación difícil; la decisión venezolana tomó a muchos por sorpresa, incluyendo políticos en ejercicio y analistas de la integración andina. Valga reconocer que la decisión me sorprendió en la mitad del camino y ya había alcanzado el punto de no retorno por lo que debí continuar el trabajo aún a riesgo de parecer desactualizado. Tradicionalmente para los políticos en el ejercicio del poder, se asumía como "políticamente incorrecto" y de un costo político importante tomar la decisión de denunciar el Acuerdo porque ello afectaba la tradicional imagen integracionista de cada país. Pero aún más específicamente y más importante, era la suposición de que el acervo comunitario en legislación y en protección frente a terceros era suficientemente sólido como para impedir el retiro cómodo o la denuncia del mismo. La legislación andina: Decisiones y Regulaciones comunes, en muchos casos, no tienen equivalentes en el derecho interno de los países bien sea por la aplicación directa y preferente de la andina o por los vacíos en la legislación nacional para regular muchos de los asuntos relacionados con el Programa de Liberación de la Subregión. La legislación andina no sólo incluye temas relacionados con el comercio, también incluye otros temas como el transporte y el desarrollo de las fronteras comunes a los cuales se renuncia en el momento mismo de denunciar el Acuerdo cuando cesan las obligaciones y los derechos (artículo 135 del Acuerdo de Cartagena).
} 
NACIONAL, 2006) se le da una visión distinta a la tradicional descentralización y reforma del Estado siguiendo los lineamientos clásicos y se opta por la participación popular en las comunidades como alternativa a la Ley de Régimen Municipal. Colombia por su parte mantiene la descentralización y la municipalización y en muchos casos se devuelven poderes a los municipios. Aunque hay críticas a la forma en que se devuelven los poderes en Colombia pues no necesariamente se otorgan los recursos a los municipios y/o las regiones, hay continuidad formal en las distribuciones de competencias y de los principios de corresponsabilidad y subsidiaridad.

La reciente denuncia del Acuerdo por parte de Venezuela deja sin efecto oportunidades de continuar desarrollando la convivencia y la solución de las diferencias en el marco de la CAN. Venezuela ha señalado que las relaciones comerciales, diplomáticas y vecinales seguirán siendo tratadas de manera binacional; por lo que queda abierta la posibilidad de continuar ejecutando las ZIFs desde lo bilateral. No obstante, debido a que la Decisión 501 deja abierta la posibilidad de crear ZIFs con terceros países y habiendo Colombia y Venezuela transitado buena parte del proceso que condujo a la creación de la ZIF Norte de Santander - Táchira siguiendo la normativa comunitaria aún es probable que Venezuela decida continuar la implementación y ejecución de la ZIF en cuestión haciendo binacional la norma comunitaria. Estas opiniones son sólo conjeturas posibles y al momento de escribir este trabajo no hay nada concreto al respecto.

La revisión realizada deja dudas sobre la profundidad del compromiso con la integración y con la reforma del Estado en Latinoamérica. Tanto la integración regional como la reforma del Estado y la descentralización han atravesado por distintos momentos en los cuales se observan las adaptaciones del pensamiento político-económico dominante en el mundo y las formas particulares que tiene la región, incluyendo sus líderes, de insertarse en el escenario internacional.

En los años sesenta del siglo XX se transitó por el regionalismo cerrado y por las reformas del Estado próximas al keynesianismo donde se le asignaba una función importante al gobierno en el diseño y ejecución de las políticas económicas. Adaptaciones latinoamericanas de la experiencia europea de integración regional y de las políticas económicas aplicadas en el mundo de 
posguerra fueron visibles en el Área de Libre Comercio de América Latina (ALALC) y el Acuerdo de Cartagena entre otros y en las polítcas y acciones de desarrollo regional aplicadas mediante las Corporaciones de Desarrollo Regional cuyos principales logro y propósitos de debieron a la acción del Estado nacional antes que a realizaciones impulsadas desde las regiones. El Acuerdo General de Aranceles y Comercio (GATT), el Fondo Monetario Internacional (FMI) y el Banco Mundial (BM), entre otros, patrocinaron políticas económicas mixtas donde a pesar de promover el libre comercio internacional no dejaban libertad absoluta a las fuerzas del mercado y procuraban garantizar la estabilidad económica a largo plazo, permitiendo una participación activa de los gobiernos en la economía. (RAPLEY, 1996) En consecuencia, el funcionamiento de los organismos multilaterales al igual que las Naciones Unidas con la Comisión Económica Para América Latina (CEPAL) asumieron programas y acciones cónsonas con esas políticas y entre ellas se incluyeron tolerancia, respaldo o apoyo, según el caso, de expresiones de regionalismo cerrado y estímulo a la puesta en marcha de políticas de planificación regional y /o regionalización político-administrativas al interior de los países. Adicionalmente, el pensamiento político y geográfico de los años sesenta y setenta tanto al interior de los países latinoamericanos y andinos estuvo bastante orientado a estimular el desarrollo de la integración y de las regiones nacionales mediante la planificación del desarrollo (MONCAYO JIMÉNEZ, 2005; BOISIER, 2005).

De la misma forma, en los años ochenta y noventa al evidenciarse el fracaso del modelo keynesiano para los países del Tercer Mundo los mismos organismos multilaterales y sus promotores consideraron que los fuertes endeudamientos para financiar planes de desarrollo les estaba conduciendo a serios problemas con el servicio de la deuda externa y los bancos acreedores. Así, el BM y el FMI unieron esfuerzos para condicionar la reestructuración de la deuda a la aplicación de lo que se conoció como el paquete de ajuste estructural, que en América fue conocido como el Consenso de Washington. (GUERRA BORGES, 2002). La Organización Mundial de Comercio (OMC) por su parte contribuyó con la promoción de la apertura comercial mientras que el BM y el FMI insistían en la necesidad del retiro del Estado de la economía, privatizaciones y descentralización político administrativa 
entre otros (RAPLEY, 1996). No es osado entonces sugerir que el regionalismo abierto y la reforma del Estado así como la descentralización infranacional sean promovidas fundamentalmente desde los organismos internacionales, las cuales han sido, hasta cierto punto, más que sugeridas a los países Latinoamericanos. Sin embargo, también sería exagerado señalar que no hubo, en cada momento, élites políticas y económicas al interior de los países dispuestas a aceptar y llevar a cabo tales lineamientos generales. Por otra parte, tampoco hay registros que indiquen que los cambios en la integración y en la descentralización hayan ocurrido en sentido contrario, es decir producto de demandas de la población regional, nacional o local, o de demandas autónomas de los gobiernos.

Es precisamente esa falta de iniciativa o de autonomía lo que influye en el desgano de los países para adoptar las políticas, programas y proyectos. Los gobiernos terminan haciendo adaptaciones nacionales a las políticas esbozadas internacionalmente y es en esas adaptaciones donde intervienen las percepciones y formas de ver el futuro de cada país actuando individualmente o como parte de una organización de integración regional en el escenario internacional. En el caso de Colombia y Venezuela como hemos revisado, son muchas las diferencias y pocos los puntos de encuentro duradero. Así, las respuestas dadas a la integración regional o a la descentralización y al desarrollo regional de las fronteras son más respuestas aparentes a la tendencia dominante ya que en realidad son simulaciones para seguir encubriendo los viejos recelos y temores que han marcado las relaciones diplomáticas y la dinámica de las fronteras comunes. 


\section{Referencias Bibliográficas}

ALADI/CEPAL/SELA. El proceso de convergencia regional y el establecimiento del ALCA. Montevideo, Uruguay: 1996.

ALTER, Karen. Who are the masters of the treaty? European Governments and the European Court of Justice. International Organization, New York, v. 52, n. 1, 1998.

ARDILA, Martha; CARDONA, Diego; TICKNER, Arlene. Prioridades y desafios de la politica exterior colombiana. Bogotá: Fundación Ebert Stiftung, Fescol \& Hanns Seidel Stiftung, 2002.

ASAMBLEA NACIONAL. Disponible en: http://www.asambleanacional.gov. ve. Consulta en: 30 sept. 2006.

ASCANIO, Jimenéz Agustín; NAVAS, Carlos et al. Venezuela y sus fronteras en la hora cero. Caracas: Cromotip, 1972.

AXLINE, W. Andrew. Cross regional comparisons and the theory of regional cooperation: lessons from Latin America, the Caribbean, South East Asia and the South Pacific. In: AXLINE, W. Andrew (Ed). The politic economy of regional cooperation: comparative case studies. London: Associated University Press, 1994.

BHAGWATI, Jagdish. Regionalism and multilateralism: an overview. In: MELLO, Jaime; PANAGARIYA, Avind (Ed.). New social dimension in regional integration. Cambridge: Cambridge University Press, 1993.

BOISIER, Sergio. Una (re) visión heterodoxa del desarrollo (territorial): un imperativo categórico. Territorios. Revista de Estudios Regionales, Bogotá, CIDER-UNIANDES, n. 10-11, 2005.

BUSTAMANTE, Ana Marlene; CARABALLO, Leonardo. Zona de Integración Fronteriza (ZIF) en Norte de Santander (Colombia) - Táchira (Venezuela). Dificultades para su creación e Implementación. Aldea Mundo, Año 10, n. 18, 2005. 
BUSTAMANTE, Ana Marleny, SIERRA, Marina. et al. Propuesta de definición y delimitación de la zona de integración fronteriza: Área Norte de Santander (Colombia) - Táchira (Venezuela). Bucaramanga: CEFI-ULA, Universidad Francisco de Paula Santander, Universidad Libre Seccional Cúcuta, 2005.

CEFI. Documento-Base. Las Fronteras y la Constituyente. A ser presentado a la Asamblea Nacional Constituyente, abril, 1999. Aldea Mundo, n. 7, año, 4, p. 59-61, 1999.

CEPAL. Fomentar la coordinación de las políticas económicas en América Latina. El método REDIMA para salir del dilema del prisionero. Chile, n. 82, 2005.

COLOMBIA INTERNACIONAL. Disponible en: http://www. colombiainternacioal.org. Consulta en: 30 jun. 2006.

COMUNIDAD ANDINA. Decisión 501, Comisión, Decisiones 3.3.5. Octava Reunión del Consejo Andino de Ministros de Relaciones Exteriores de la Comunidad Andina. Valencia, 22 de junio de 2001.

. Disponible en: http://www.comunidadandina.org. Consulta en: enero 2006.

- Declaración de Galápagos, 1998. Disponible en: http://www. comunidadandina.org/normativa. Consulta en: marzo 2006.

. Lo relacionado a decisiones de la CAN hasta 2006. Disponible en: http://www.comunidadandina.org/documentos.

CONSEJO CONSULTIVO LABORAL ANDINO. Disponible en: http:// www.ccla.org.pe. Consulta en: 30 sept. 2006.

EL NACIONAL EN LÍNEA. Disponible en: http://www.el-nacional.com. Consulta en: 2 abr. 2006.

FINOT, Ivan. Descentralización en América Latina. Teoría y práctica, ILPES/ CEPAL, Serie Gestión Pública Santiago de Chile, n. 12. In: MONCAYO JIMÉNEZ, Edgar. Geografía económica de la Comunidad Andina. Regiones: nuevos actores de la integración. Lima: SG-CAN, 2003.

FRAMBES-BUXEDA, Aline. Moving towards a sociology and theory of subordinate integration. Implications for Latin America and North America. Paper Presented in the XVIII Congress of LASA, Atlanta, Mar. 1994. 
GEORGE, Stephen. Politics and polity in the European Community. 2. ed. New York: Oxford University Press, 1991.

GUERRA BORGES, Alfredo. ¿Tiene Futuro la integración Económica de América Latina? In: BRICEÑO, R. José; BUSTAMANTE, Ana Marlene (Coord.). La integración latinoamericana. Entre el regionalismo abierto y la globalización. Mérida: CEFI-ULA, 2002.

HAAS, Ernst. The Uniting of Europe and the Uniting of Latin America. Journal of Common Market Studies, London, v. V, n. 4, p. 325-340, 1967.

HURREL, Andrew. Regionalism in theoretical perspective. In: FAWCETT, Louise; HURREL, Andrew (Eds.). Regional organizations and international order. Oxford: Oxford University Press, 1995.

IBARRA, David. Los laberintos del orden internacional: la importación de las reformas. Revista de la CEPAL, Chile, n. 82, 2004.

ICE. Venezuela y el Pacto Andino. Documentos y controversia. Caracas: Indal, 1974.

KAPLAN, Marcos. El Estado en la integración y el desarrollo de América Latina. Caracas: Monte Ávila Editores, 1969.

. Problemas del desarrollo y de la integración en América Latina. Caracas: Monte Ávila editores, 1976.

.Aspectos del Estado en América Latina. México: Instituto de Investigaciones Jurídicas, UNAM, 1989.

KATZENSTEIN, Peter J. Regionalism in a comparative perspective. In: KATZENSTEIN, Peter; SHIRAISHI, Takashi (Eds.). Network power: Japan and Asia. Ithaca: Cornell University Press, 1997.

LA NACIÓN. Publicación Diaria del estado Táchira. Disponible en: http:// www.lanación.com. Consulta en: abr.-jun. 2006.

LINDBERG, Leon. Political integration, definitions and hypothesis, 1963. In: NELSEN, Brent F.; STUBB, Alexander C-G (Eds.). The European Union. Readings on the theory and practice of european integration. London: Lynne Rienner Publishers, 1994. 
MARKS, Gary; HOOGE, Liesbeth; BLANK, K. European integration from the 1980s: state-centric V. Multi-Level Governance. Journal of Common Market Studies, London, v. 34, n. 3, 1996.

MILWARD, Allan. The european rescue of the nation-state. London: Routledge, 1994.

MONCAYO JIMÉNEZ, Edgar. Elementos para una estrategia de desarrollo territorial en el marco de la integración andina. Documento de Trabajo elaborado para la CG-CAN. Lima: p. 46-65, 2005.

MONTERO, Maritza. Ideología, alineación e identidad nacional: una aproximación psicosocial al ser venezolano. Caracas: Universidad Central de Venezuela, Ediciones de la Biblioteca, 1997.

MORAVCSICK, A. Preferences and power in the European Community: a liberal intergovernmental approach. Journal of Common Market Studies, London, v. 31, p.473-524, 1993.

PAYNE, Anthony. The United States and its Enterprise for the Americas. In: GAMBLE, Andrew; PAYNE, Anthony (Eds.). Regionalism and world order. London: Macmillan Press, 1996.

PELKMANS, Jacques. Comparando las integraciones económicas: prerrequisitos, opciones e implicaciones. La integración regional en América Latina y Europa: objetivos, estrategias y refuerzo de la capacidad de respuesta. Uruguay: CEFIR, 1993. Consulta en: http://www.cefir.org.uy.

QUINTERO, Inés. La tradición grancolombiana: hito y mito en la relación colombo-venezolana. In: RAMÍREZ, Socorro; CADENAS, José Maria. Venezuela y Colombia. Debates de la historia y retos del presente. Caracas: UCV, IEPRI - Universidad Nacional, Ministerio de Ciencia y Tecnología, 2005.

RAMÍREZ, Socorro; HERNÁNDEZ, Miguel Angel. Colombia y Venezuela: vecinos cercanos y distantes. In: RAMÍREZ Socorro; CADENAS, José Maria. (Coord.). La vecindad colombo-venezolana. Imágenes y realidades. Bogotá: CAB, UCV, Universidad Nacional, 2003. 
RAMÍREZ, Socorro; ROMERO, Carlos; SANJUÁN, Ana María. Estados Unidos - Colombia - Venezuela: ¿una relación triangular? In: RAMÍREZ, Socorro; CADENAS, José Maria. Venezuela y Colombia. Debates de la historia y retos del presente. Caracas: UCV, IEPRI - Universidad Nacional, Ministerio de Ciencia y Tecnología, 2005.

RAPLEY, John. Understanding development. Theory and practice in the third world. London: Rienner, 1996.

RAVENHILL, John. The Growth of intergovenmentalism collaboration in the Asia-Pacific. In: McGrew, Anthony; BROOK, Christopher (Eds.). Asia Pacific in the new world order. London, New York, Routledge, 1998.

REPÚBLICA BOLIVARIANA DE VENEZUELA. Constitución de la República Bolivariana de Venezuela. Caracas: 1999. . Ley Orgánica del Poder Municipal, Caracas: 2005.

REPÚBLICA DE COLOMBIA. Constitución Política de la República de Colombia. Bogotá: 1991.

SALAZAR, J. Bases psicológicas del nacionalismo. México: Editorial Trillas, 1983.

SIDERI, Sandro. Globalization and Regional Integration. Working Paper Series, The Netherlands, Institute of Social Studies, n. 235, 1996.

STEIN, Stanley; STEIN, Barbara. La herencia colonial de América Latina, 11. ed. México: Siglo XXI, 1979. 